\title{
Should We Care About the Uncertainty Around Measures of Political-Economic Development?
}

\author{
Rodolphe Desbordes ${ }^{\ddagger} \quad$ Gary Koop K $^{\S}$
}

\begin{abstract}
Several proxies of political-economic development, such as the Worldwide Governance Indicators, come in the form of an estimate along with a standard error reflecting the uncertainty of this estimate. Existing empirical work discards the information provided by the standard errors. We argue that the appropriate practice should be to take into account this additional information through the use of multiple imputation. We investigate the importance of our proposed approach in several applications. We find that accounting for the uncertainty around the values of various measures of political-economic development tends to have a large influence on the magnitude and statistical significance of the estimated effects of these variables.
\end{abstract}

JEL classification: C1, F1, F2, O11. Keywords: democracy; income inequality; governance; multiple imputation; uncertainty.

\footnotetext{
${ }^{\ddagger}$ Corresponding author. University of Strathclyde. Address: Department of Economics, Sir William Duncan Building, University of Strathclyde, 130 Rottenrow, Glasgow G4 0GE, Scotland, United Kingdom. Telephone/Fax number: +44 141548 3961/+44 141548 5776. E-mail: rodolphe.desbordes@strath.ac.uk

$\S$ University of Strathclyde. gary.koop@strath.ac.uk
} 


\section{Introduction}

In the economic growth and development literature it is common to use proxies for key measures of political-economic development such as governance or democracy. For example, the Worldwide Governance Indicators (WGI) are widely used to assess institutional quality (see Kaufmann et al. $(1999,2011))$. The WGI project provides quantitative information on six dimensions of governance, by averaging in a statistically sophisticated manner a very large number of underlying variables coming from thirty-two independent data sources. The estimates provided are commonly included in econometric models. The creators of the WGI (and the creators of aggregate governance indicators based on extensions of the WGI method-

ology) have consistently stressed the uncertainty of their governance estimates and provide a standard error for each estimate. Several papers have used these standard errors in empirical exercises such as interpreting country rankings (see, e.g., Kaufmann and Kraay (2002), Treisman (2007), Høyland et al. (2012), and Standaert (forthcoming)). However, to our knowledge, no use has been made of the information in the WGI standard errors in the regressions and panel data models that are the main econometric tools used in the growth and development literatures. This paper aims to fill this gap. We use multiple imputation methods to investigate whether failing to take into account the information on the uncertainty of WGI and other measures of political-economic development is an important issue.

We first explain how multiple imputation can be used to take into account the additional information provided by the WGI standard errors. We then investigate the relevance of our suggested approach in several applications. The first two of these applications investigate the impacts of governance on capital flows and international trade, respectively. The third repeats the classic colonial origins exercise of Acemoglu et al. (2001) and the fourth investigates the relationship between recently created proxies of democracy and inequality. We find that accounting for the uncertainty around the values of various measures of political-economic 
development has, in some cases, a large influence on empirical results.

The remainder of this paper is organized as follows. Section 2 describes our econometric approach. Section 3 presents our applications. Section 4 concludes.

\section{Generated Variables and Multiple Imputation}

Generated variables are those constructed using a first-step model which are then used in a regression. A standard practice is to bootstrap the standard errors of the parameter estimates, in order to take into account the fact that generated variables are measured with error (Wooldridge, 2010). In the absence of additional information, this is certainly the best that the researcher can do. However, for some variables, such as the WGI, uncertainty about their values is provided, in the form of standard errors. This additional information can be exploited, as we explain below.

To describe the main issues, consider a regression model with dependent variable, $y$, explanatory variable, $x^{*}$, coefficients $\beta$ and error variance $\sigma^{2}$. Subscripts $i=1, . ., N$ denote individual observations. Our proxy for $x_{i}^{*}$ is the generated regressor $x_{i}$ and $x_{i}^{*} \sim N\left(x_{i}, \sigma_{x_{i}}^{2}\right){ }^{1}$ For some variables, such as those produced by the WGI project, standard errors, $\sigma_{x_{i}}^{2}$, are provided. Researchers usually focus on $x_{i}$ only. However, a natural way to take into account the information provided by $\sigma_{x_{i}}^{2}$ is to adopt a Bayesian perspective where inference is based on a posterior density (i.e. a density for any model parameters conditional on the data set). Ideally, we wish to have inference based on the posterior conditional on the true value of the

\footnotetext{
${ }^{1}$ This interpretation is consistent with Kaufmann et al. (2009) which states on page 16: "the output of our aggregation procedure is a distribution of possible values of governance for a country, conditional on the observed data for that country. The mean of this conditional distribution is our estimate of governance, and we refer to the standard deviation of this conditional distribution as the "standard error" of the governance estimate." The normality assumption derives from page 9. In the case of the WGI, Kaufmann et al. (1999) show that adopting alternative distributions of governance would yield estimates and standard errors qualitatively similar to those obtained under the assumption of normality.
} 
explanatory variable: $p\left(\beta, \sigma^{2} \mid y, x^{*}\right)$. However, $x^{*}$ is not known with certainty. All we know is the distribution of $x^{*}$ conditional on the information that was used to compute the WGI (call this $z): p\left(x^{*} \mid z\right)$. Thus, we need to work with the posterior: $p\left(\beta, \sigma^{2} \mid y, z\right)$. Given the structure of our problem, where $z$ is only used to construct the WGI variables and does not directly enter the regression, this posterior can be written as:

$$
p\left(\beta, \sigma^{2} \mid y, z\right)=\int p\left(\beta, \sigma^{2} \mid y, x^{*}\right) p\left(x^{*} \mid z\right) d x^{*}
$$

As outlined below, multiple imputation can be used to calculate this posterior. In contrast, a researcher who ignores the uncertainty about the WGI and uses $x$ as an explanatory variable bases inference on the posterior:

$$
p\left(\beta, \sigma^{2} \mid y, x\right)=p\left(\beta, \sigma^{2} \mid y, x^{*}=x\right) .
$$

Put simply, $p\left(\beta, \sigma^{2} \mid y, z\right)$ and $p\left(\beta, \sigma^{2} \mid y, x\right)$ are different posteriors and, hence, the will lead to different inference. The exact relationship between these two posterior is theoretically unclear. We might expect them to be similar to one another, but with $p\left(\beta, \sigma^{2} \mid y, z\right)$ leading to larger measures of dispersion than $p\left(\beta, \sigma^{2} \mid y, x\right)$ due to the incorporation of the uncertainty surrounding the WGI variables. We often do find this result, but theoretically other outcomes are possible and a purpose of this paper is to investigate how much $p\left(\beta, \sigma^{2} \mid y, z\right)$ and $p\left(\beta, \sigma^{2} \mid y, x\right)$ diverge from one another in practice.

In order to draw inference on $p\left(\beta, \sigma^{2} \mid y, z\right)$ we need to evaluate the integral in (1). This can be done using an averaging procedure, where many regressions have been run, using different plausible values of the variable of interest. In our case, the fact that the WGI project provides us with $p\left(x^{*} \mid z\right)$ means that the averaging can be done in a very simple fashion:

i Simulate $s=1, . ., S$ draws $x_{i}^{*(s)}$ for $i=1, . ., N$ from the $N\left(x_{i}, \sigma_{x_{i}}^{2}\right)$ distribution. 
ii For each of these draws, use the posterior $p\left(\beta, \sigma^{2} \mid y, x^{*(s)}\right)$ to carry out the desired econometric inference.

iii Average inferences over all $S$ estimates produced in step 2.

The strategy outlined in the three steps also goes by the name of multiple imputation and the draws of Step 1 are called imputations. Multiple imputation was developed as a tool for estimating a variety of models where variables have missing values (see, e.g., Rubin (1996)). The use of generated variables can be interpreted as a kind of missing data problem (i.e. where the variable of interest, $x^{*}$, is missing but information is known about its distribution).

Bayesian econometrics have gained in popularity in the last two decades but the frequentist paradigm still dominates the empirical literature. Fortunately, multiple imputation is compatible with frequentist estimators and can be implemented in standard econometric software like Stata. ${ }^{2}$ For the frequentist, values of $x_{i}^{*}$ can still be imputed as in step 1 and used in a multiple imputation procedure. The only difference with the Bayesian approach that we outlined above is that a frequentist estimator is used in step 2.

To summarize, the existing empirical literature uses $x_{i}$ as proxy variable. This does not lead to inconsistent estimators of the parameters but such a procedure, including when it involves parametric bootstrap, ignores the uncertainty in the proxy variable. Ideally, one would want to use the entire distribution of $x_{i}^{*}$ as the proxy variable, given that it contains useful information about the uncertainty associated with calculating the generated values, and not $x_{i}$. Multiple imputation is a method which allows us to do this. In practice, results produced using multiple imputation can differ markedly from non-multiply-imputed results, even if the latter are not inconsistent. It is worth stressing that multiple imputation influences both point estimates and standard errors, although the direction of influence is theoretically

\footnotetext{
${ }^{2}$ A pseudo-code showing how to implement our suggested approach in Stata is described in Appendix B.
} 
unclear. In other words, estimates and standard errors could either be smaller or larger than those produced without multiple imputation. ${ }^{3}$

So far, we have discussed the econometric theory when there is a single, cross-sectional explanatory variable, $x_{i}^{*}$. The researcher may want to multiply impute several explanatory variables. In such a case, we would want to allow for the fact that they could be correlated with one another (e.g. if they were derived from over-lapping data sources). Similarly, in panel or time series contexts, we would want to allow for the fact that imputations of a given variable at different time periods may be correlated with one another. The WGI data set we use does not allow us to handle either type of correlation and we are implicitly assuming our multiply-imputed variables are independent of each other and over time. Standaert (forthcoming) discusses both these issues and their consequences in detail. In particular, he shows that the value of a WGI for an individual country can be highly autocorrelated over time. He demonstrates that when this fact is ignored, the significance of changes over time in a country's WGI will be under-estimated. Intuitively, for a given country, imputations for two different time periods should be taken from a bivariate distribution with a positive correlation. The positive correlation will increase the chances of imputing similar values for the WGI in the two time periods. By implicitly assuming a zero correlation, our panel data applications are missing this feature and are using imputations that are less similar (across time) than they should be. A similar line of reasoning implies that, in our application which uses more than one WGI indicator, the correlations between our imputed explanatory variables are lower than they should be.

We also note that, in one application, we are imputing an average WGI. At each impu-

\footnotetext{
${ }^{3}$ Multiply imputed standard errors involve a within-imputation component (average of variance estimates) and a between-imputation component (variance of the estimated coefficients across imputations). Intuitively, we can expect multiply imputed standard errors to be larger than non-imputed standard errors due to the second component. However, it is possible that multiply imputed standard errors are smaller than non-imputed standard errors if the within-imputation component becomes relatively small, due to larger sample variation in the imputed variable.
} 
tation we draw from each of the six individual WGI (assuming independence) and average the result. By ignoring the positive correlation between the indicators, we will be underestimating the uncertainty associated with this average WGI. ${ }^{4}$

Given the nature of our data, we can only note these issues and suggest the reader keep them in mind when interpreting our results.

\section{Empirical applications}

In this section, we consider several different empirical applications involving prominent generated political-economic variables, for which estimates and measures of uncertainty such as standard errors are provided. These proxy variables are related to the quality of governance, the democratic nature of a country's political regime, and the level of income inequality. Each application contains only a brief summary of the relevant aspects of the data. However, Table 6 in Appendix A provides complete definitions, sources and measurement units for all of our variables.

The WGI, which are at the heart of most of our empirical applications, are widely used proxies of political-economic development in the literature. The WGI project reports aggregate indicators for six dimensions of public governance: Voice and Accountability (VA); Political Stability (PS); Government Effectiveness (GE); Regulatory Quality (RQ); Rule of Law (RL); Control of Corruption (CC). VA and PS attempt to capture the process by which those in authority are selected and replaced, GE and RQ are related to the ability of the government to formulate and implement sound policies, while RL and CC assess the respect of citizens and the state for the institutions which govern them. ${ }^{5}$ Each indicator is a weighted

\footnotetext{
${ }^{4}$ This follows from the fact that, for two random variables, $a$ and $b$, var $(a+b)=\operatorname{var}(a)+\operatorname{var}(b)+$ $2 \operatorname{cov}(a, b)$. We are instead implicitly assuming $\operatorname{var}(a+b)=\operatorname{var}(a)+\operatorname{var}(b)$ and working with a variance which is too small.

${ }^{5}$ For more information, see Kaufmann et al. (2011) and the resources at www.govindicators.org/
} 
combination of a large number of different data sources, capturing the views and experiences of survey respondents and experts. Values for each governance indicator range from around -2.5 to 2.5 and are available over the period 1996-2012 for 215 countries.

As emphasized in, e.g., Kaufmann et al. (2011), although the point estimates of the governance indicators vary substantially across countries and over time, interval estimates can overlap substantially. Overall, there is a high degree of uncertainty of these variables, but not so high as to preclude making meaningful comparisons for many countries either in the cross section (e.g. differences in governance between many pairs of countries are statistically significant) or, to a lesser extent, in the time series dimension (e.g. some countries exhibit statistically significant changes in governance over time).

In our applications, we are interested in finding out whether explicitly accounting for the uncertainty in these estimates will substantially affect empirical results. For each application, we report the standard estimates produced ignoring the generated regressor issue followed by multiple imputation results. For the former, we also provide bootstrapped standard errors in brackets. As expected, these are larger than the uncorrected standard errors, but only rarely to such a degree as to alter conclusions about the statistical significance of coefficients. On the other hand, our empirical applications show that the results produced using multiple imputation often vary substantially from conventional estimates, casting doubt on the robustness of findings ignoring uncertainty about various measures of political-economic development.

\subsection{Capital flows and governance}

\subsubsection{Data and empirical approach}

In a recent paper, Binici et al. (2010) primarily investigate the impact of inward and outward capital controls on debt and equity flows. Nevertheless, among their key results, they find 
that higher institutional quality, as measured by the average of the six WGI, increases inflows and decreases outflows for both debt and equity. These results echo those of Daude and Stein (2007), Alfaro et al. (2008), Faria and Mauro (2009), and Azémar and Desbordes (2013). They have been frequently interpreted as providing a partial answer to the Lucas Paradox. Poor countries do not attract large equity inflows because of the low productivity induced by their poor governance.

In Binici et al. (2010), the dependent variable is the log of financial flows per capita; these financial flows can be equity inflows, debt inflows, equity outflows or debt outflows. The explanatory variables are de jure capital account restrictions, various control variables and the average of the six WGI. ${ }^{6}$ Like them, we omit oil-exporting countries and keep our sample constant across regressions. Overall, our sample covers 71 countries over the period 1998-2005. ${ }^{7}$ We re-examine the regressions of Table 3 of their paper. Binici et al. (2010) estimate their log-linearized model using a fixed effects OLS estimator and a sample devoid of zero values. We we do the same. Standard errors are clustered at the country level.

\subsubsection{Results}

Our results are presented in Table 1. In the upper panel, columns (1)-(4) are regressions the most comparable to those carried out by Binici et al. (2010) in Table 3 of their paper. The multiple imputation results are provided in the lower panel of Table 1 in columns (1')-(4').

The results of columns (1-4) mirror, at least in qualitative terms, Binici et al. (2010)'s key

\footnotetext{
${ }^{6}$ They use the average of the percentile rank of the six indicators. Thus, we retain cardinal information which would be lost with ranking. Furthermore, we avoid the possibility of a fall in the percentile rank despite better governance. Finally, percentile ranking is sensitive to the introduction of new countries. Nevertheless, in unreported regressions, we find that our key results are unchanged when we use the average of the percentile rank of the six indicators as the measure of institutional quality.

${ }^{7}$ They report having data over the period 1995-2005. However, data on debt inflow/outflow restrictions are only available from 1997. In addition, the number of observations that they report (727) seem very high given that values for the governance variables are missing for the years 1995, 1997, 1999, 2001. Assuming no other missing data, the number of observations in their sample ought to have been $518(74$ [countries] $\times 7$ [years])).
} 
Table 1: Capital flows and governance

\begin{tabular}{|c|c|c|c|c|}
\hline & \multicolumn{2}{|c|}{ Debt securities } & \multicolumn{2}{|c|}{ FDI+portfolio equity } \\
\hline & Inflow & Outflow & Inflow & Outflow \\
\hline & \multicolumn{4}{|c|}{$\ln$ (flow/population); Within estimator } \\
\hline & (1) & $(2)$ & $(3)$ & $(4)$ \\
\hline Average six WGI & $\begin{array}{l}1.190 * \\
(0.660) \\
{[0.765]}\end{array}$ & $\begin{array}{l}-0.483 \\
(0.606) \\
{[0.665]}\end{array}$ & $\begin{array}{l}1.924 * * * \\
(0.714) \\
{[0.745]^{* * *}}\end{array}$ & $\begin{array}{l}-1.757 * * * \\
(0.625) \\
{[0.706]^{* *}}\end{array}$ \\
\hline $\ln ($ GDP per cap) & $\begin{array}{l}4.796^{* * * *} \\
(1.302) \\
{[1.415]^{* * *}}\end{array}$ & $\begin{array}{l}3.395 * * * \\
(0.928) \\
{[0.947]^{* * *}}\end{array}$ & $\begin{array}{l}4.184 * * * \\
(1.487) \\
{[1.571] * * *}\end{array}$ & $\begin{array}{l}4.951 * * * \\
(1.383) \\
{[1.494]^{* * *}}\end{array}$ \\
\hline Capital in/out-flow controls & $\begin{array}{l}-0.354 \\
(0.344) \\
{[0.393]}\end{array}$ & $\begin{array}{l}-0.473^{*} \\
(0.253) \\
{[0.280]^{*}}\end{array}$ & $\begin{array}{l}-0.361 \\
(0.492) \\
{[0.500]}\end{array}$ & $\begin{array}{l}-0.644 * \\
(0.357) \\
{[0.409]}\end{array}$ \\
\hline Private credit/GDP & $\begin{array}{l}0.131 \\
(0.707) \\
{[0.792]}\end{array}$ & $\begin{array}{l}1.123 \\
(0.682) \\
{[0.756]}\end{array}$ & $\begin{array}{l}0.198 \\
(0.593) \\
{[0.729]}\end{array}$ & $\begin{array}{l}0.836 * \\
(0.487) \\
{[0.526]}\end{array}$ \\
\hline STMK CAP/GDP & $\begin{array}{l}-0.439 \\
(0.419) \\
{[0.496]}\end{array}$ & $\begin{array}{l}-0.151 \\
(0.395)\end{array}$ & $\begin{array}{l}0.137 \\
(0.447)\end{array}$ & $\begin{array}{l}0.615^{* *} \\
(0.266)\end{array}$ \\
\hline (Fuel,Metals,Ore)/Exports & $\begin{array}{l}{[0.490]} \\
-2.831 \\
(2.891) \\
{[3.207]}\end{array}$ & $\begin{array}{l}{[0.451]} \\
2.941 \\
(2.055) \\
{[2.213]}\end{array}$ & $\begin{array}{l}{[0.509]} \\
3.146 \\
(3.451) \\
{[3.700]}\end{array}$ & $\begin{array}{l}{[0.328]^{*}} \\
-2.190 \\
(2.360) \\
{[2.552]}\end{array}$ \\
\hline Trade openness & $\begin{array}{l}-1.700 * * \\
(0.806) \\
{[1.005]^{*}}\end{array}$ & $\begin{array}{l}-0.806 \\
(0.564) \\
{[0.679]}\end{array}$ & $\begin{array}{l}-0.964 \\
(0.782) \\
{[0.980]}\end{array}$ & $\begin{array}{l}-0.101 \\
(0.749) \\
{[0.935]}\end{array}$ \\
\hline
\end{tabular}

With WGI uncertainty

\begin{tabular}{|c|c|c|c|c|}
\hline & $\left(1^{\prime}\right)$ & $\left(2^{\prime}\right)$ & $\left(3^{\prime}\right)$ & $\left(4^{\prime}\right)$ \\
\hline Average six WGI & 0.203 & $\begin{array}{l}-0.109 \\
(0.335)\end{array}$ & 0.366 & -0.365 \\
\hline $\ln ($ GDP per cap) & $\begin{array}{l}5.026 * * * \\
(1.303)\end{array}$ & $\begin{array}{l}3.317 * * * \\
(0.942)\end{array}$ & $\begin{array}{l}4.607 * * * \\
(1.506)\end{array}$ & $\begin{array}{l}4.555 * * * \\
(1.404)\end{array}$ \\
\hline Capital in/out-flow controls & $\begin{array}{l}-0.468 \\
(0.348)\end{array}$ & $\begin{array}{l}-0.435 \\
(0.263)\end{array}$ & $\begin{array}{l}-0.394 \\
(0.538)\end{array}$ & $\begin{array}{l}-0.645^{*} \\
(0.356)\end{array}$ \\
\hline Private credit/GDP & $\begin{array}{l}0.089 \\
(0.726)\end{array}$ & $\begin{array}{l}1.142 * \\
(0.676)\end{array}$ & $\begin{array}{l}0.121 \\
(0.604)\end{array}$ & $\begin{array}{l}0.909 * \\
(0.495)\end{array}$ \\
\hline STMK CAP/GDP & $\begin{array}{l}-0.329 \\
(0.413)\end{array}$ & $\begin{array}{l}-0.193 \\
(0.404)\end{array}$ & $\begin{array}{l}0.313 \\
(0.462)\end{array}$ & $\begin{array}{l}0.455 \\
(0.283)\end{array}$ \\
\hline (Fuel,Metals,Ore)/Exports & $\begin{array}{l}-3.408 \\
(2.940)\end{array}$ & $\begin{array}{l}3.116 \\
(2.070)\end{array}$ & $\begin{array}{l}2.204 \\
(3.806)\end{array}$ & $\begin{array}{l}-1.340 \\
(2.890)\end{array}$ \\
\hline Trade openness & $\begin{array}{l}-1.705^{* *} \\
(0.850)\end{array}$ & $\begin{array}{l}-0.807 \\
(0.559)\end{array}$ & $\begin{array}{l}-0.976 \\
(0.842)\end{array}$ & $\begin{array}{l}-0.083 \\
(0.745)\end{array}$ \\
\hline Observations & 300 & 300 & 300 & 300 \\
\hline
\end{tabular}


findings. We find that restrictions on capital outflows appear to be much more effective than restrictions on capital inflows and that higher institutional quality tends to encourage capital inflows and discourage capital inflows. ${ }^{8}$ However, columns (1')-(4') present a very different picture once we take into account the uncertainty with which the governance variables are measured. In all columns, the estimated coefficient on institutional quality becomes much smaller and is no longer statistically significant at conventional levels, despite smaller standard errors. ${ }^{9}$ Furthermore, the estimated coefficients on some of the non-imputed variables also lose statistical significance, e.g. capital controls in column (2').

Overall, we find that Binici et al. (2010)'s key findings are not robust to accounting explicitly for the uncertainty of the WGI. Our multiple imputation approach leads to a very large fall in the magnitude of the estimated coefficient on the governance variable, rendering it statistically insignificant. This is possibly because the fixed effects estimator relies solely on time-series variation in the data for identification of the parameters, and, as discussed previously, changes in the WGI can be extremely noisy variables once the uncertainty of these indicators is taken into account.

\subsection{International trade and governance}

\subsubsection{Data and empirical approach}

Berden et al. (2014) investigate the impact of governance on international trade. ${ }^{10}$ They estimate gravity equations in which they include, on the destination (importing) side, the six WGI separately in order to isolate their respective impacts. They find that VA and PS both reduce trade overall, whereas RQ increases it. Other WGI (GE, RL, CC) are not statistically

\footnotetext{
${ }^{8}$ Results for the other control variables are also very similar across the two studies.

${ }^{9}$ These smaller standard errors are likely to be the outcome of greater variation in the data when using multiple imputation.

${ }^{10}$ They also look at the impact of governance on foreign direct investment.
} 
significant. They conclude that democracy reduces trade when its main effect is to give more voice to those likely to be affected by international competition, e.g. unskilled workers. ${ }^{11}$

In Berden et al. (2014), the dependent variable corresponds to bilateral exports. The explanatory variables are those which are traditionally found in gravity-type equations (GDP, GDP per capita, bilateral distance, contiguity, common language, colonial history, proxies for multilateral resistance) and the six WGI. ${ }^{12}$ They use trade data for the period 1997-2004. We simply use all the trade data available in our data source for the same time period. Our dataset includes bilateral trade between 180 countries across five years (1998, 2000, 2002, 2003 , 2004). We re-examine one of the main regressions in their paper which is presented in column (6) of their Table 8. In a second stage, we also investigate the impact of exporting countries' governance on bilateral trade. Like Berden et al. (2014), our estimator is the pooled Poisson quasi-maximum likelihood estimator (QMLE) and standard errors are clustered at the importing country level.

\subsubsection{Empirical results}

Our results are presented in Tables 2 and 3. Column (1) is the regression the most comparable to that estimated by Berden et al. (2014) in column (6) of Table 8 in their paper. In column (2), we include the WGI on the exporting side. Columns (1')-(2') provide the multiple imputation results.

The results of column (1) echo the key finding of Berden et al. (2014): destination VA has a strong, negative, and statistically significant impact on trade. ${ }^{13}$ On the other hand, we fail

\footnotetext{
${ }^{11}$ This result contrasts with previous literature, which has typically found a positive relationship between democracy and trade openness (Milner and Mukherjee, 2009). The authors argue that is because earlier works did not specifically focus on the pluralism dimension of democracy.

${ }^{12} \mathrm{As}$ in the previous application, the authors use their percentile rank while we use their mean. In unreported regressions, we find that our key results hold when we use the percentile rank of the six WGI.

${ }^{13}$ Results for the other control variables are also very similar across the two studies.
} 
Table 2: Bilateral trade flows and governance

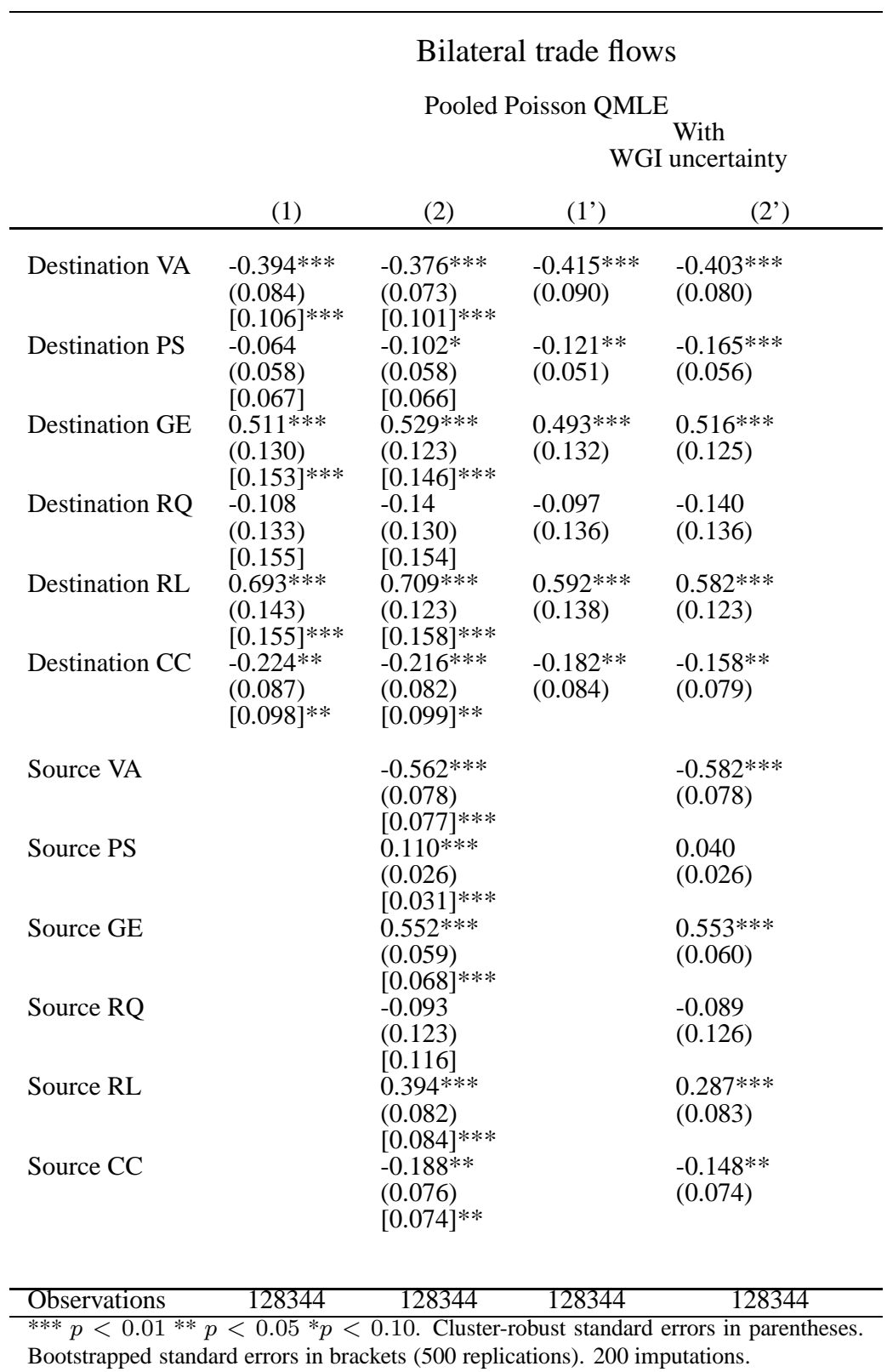


Table 3: Bilateral trade flows and governance, continued

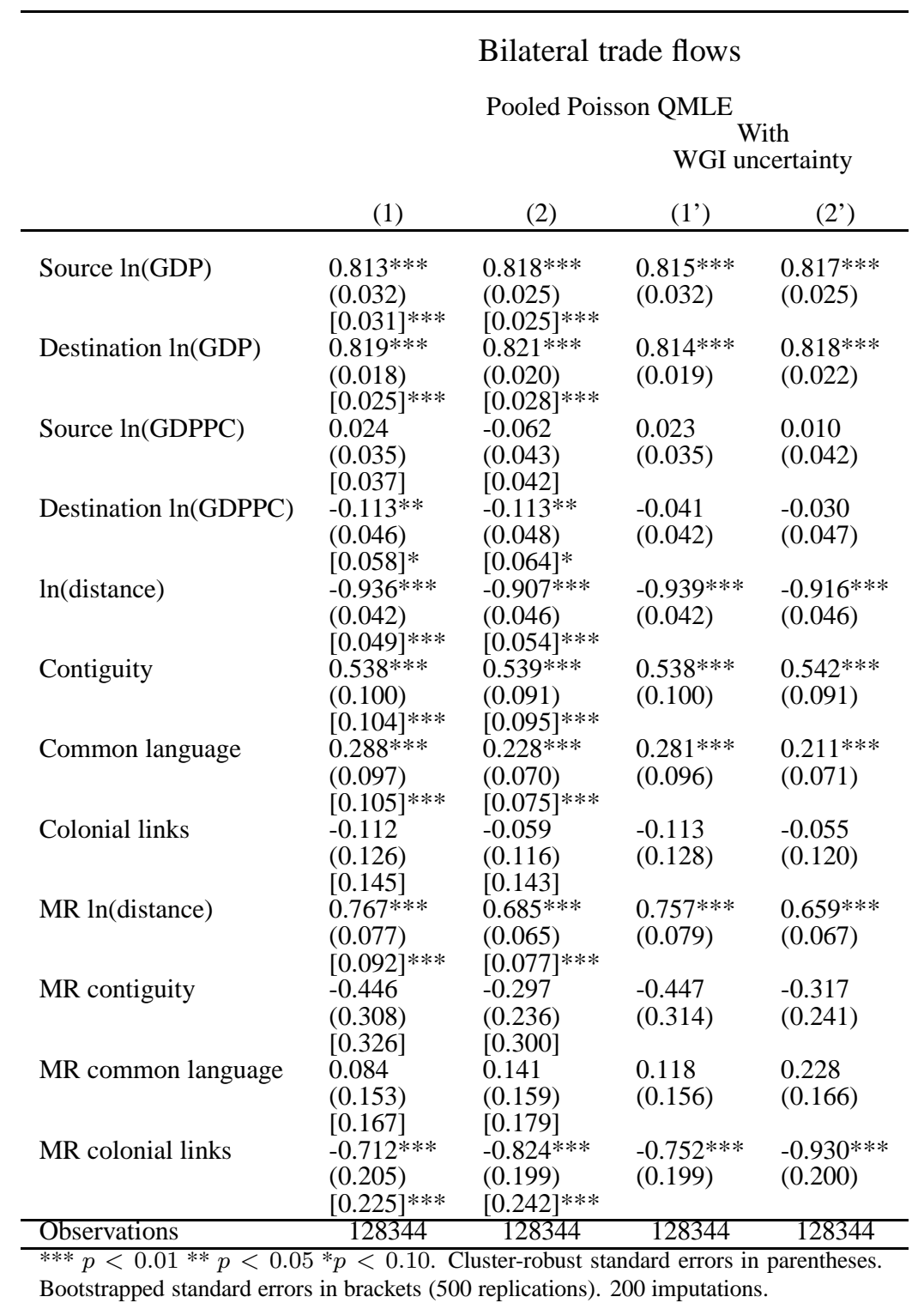


to find a statistically significant relationship between trade and destination PS or destination RQ. Introducing the WGI on the exporting side in column (2) does not change these results and, overall, imports and exports are influenced in the same way by the various governance dimensions.

Relative to what happened in our previous application, our multiple imputation approach has a much more nuanced influence on the non-imputed results here. In columns (1') and (2'), the estimated coefficients on VA/GE/RQ/RL/CC, on both exporting and importing sides, are very similar to those found in columns (1) and (2). On the other hand, in the case of destination PS, its estimated coefficient becomes larger and now statistically significant at the $5 \%$ level whereas the opposite is true for the estimated coefficient on source PS. Interestingly, the estimated coefficient on importing country's GDP per capita becomes much smaller and loses statistical significance with multiple imputation.

Overall, we find that the key findings of Berden et al. (2014) are robust to accounting explicitly for the uncertainty of the VA indicator. This is possibly due to the use of a pooled estimator, which exploits both the cross-sectional and time-series dimensions of VA. As discussed previously, differences in governance are much larger, in economic and statistical terms, between countries than within countries. Hence, the use of a pooled estimator may improve the informativeness of the WGI regarding the true governance conditions. It is worth noting that our conclusion would have been different if Berden et al. (2014) had focused on destination PS; with multiple imputation, its estimated coefficient becomes much larger and statistically significant at conventional levels. 


\subsection{Income levels and governance}

\subsubsection{Data and empirical approach}

In a seminal paper, Acemoglu et al. (2001) show that governance is a strong determinant of economic development. They establish causality by using an instrumental variable (IV) approach. The instrument for governance is the log of settler mortality. Acemoglu et al. (2001)'s key intuition is that Europeans were more likely to replicate European institutions in places suitable to large settlements and, at the other extreme, to implement extractive institutions in inhospitable environments.

Acemoglu et al. (2001) regress the log of GDP per capita in 1995 (\$ PPP), on an instrumented measure of institutional quality (the protection against "risk of expropriation" index from Political Risk Service) and the absolute latitude of a country in column (2) of Table 4 of their paper. We use the same data as they do, with the slight modification that our proxy for governance is the WGI RL values for the year 1996. Data are available for 64 countries. Standard errors are heteroskedasticity-robust.

\subsubsection{Empirical results}

Our results are presented in Tables 4. Column (1) corresponds to Acemoglu et al. (2001)'s baseline model estimated by OLS. In column (2), the same model is estimated by IV. In column (3), we remove from the sample Neo-Europes (Australia, Canada, New Zealand, the United States). In column (4), we include regional dummy variables (Africa, East Asia, Latin America). Columns (1')-(4') provide the multiple imputation results. First-stage estimates and weak instrument diagnostics are also reported. The latter correspond to the first-stage $F$ statistic $^{14}$ and the Anderson-Rubin (AR) $95 \%$ confidence interval, which is valid even

\footnotetext{
${ }^{14}$ Instruments are usually said to be strong (relevant) when the value of the $F$ statistic is around 10 or higher (Staiger and Stock, 1997). A less strict rule of thumb is $F>5$.
} 
when the instrument is weakly correlated with the endogenous variable (Chernozhukov and Hansen, 2008). For the multiply-imputed regressions, we report the averages across 200 imputations of the lower and upper bounds of the Wald and AR confidence intervals. ${ }^{15}$

The estimates reported in columns (1)-(4) are very much in line with Acemoglu et al. (2001)'s findings. Whichever the robustness check used, governance has a causal and substantial positive impact on income per capita and setter mortality is a relevant instrument. In column (4), the value of the first-stage $F$-statistic declines when we control for regional dummy variables, the AR confidence interval increases, but we still cannot reject the hypothesis that governance has no effect on income per capita.

Taking into account the uncertainty around the RL indicator makes little difference to the second-stage estimates but leads to larger standard errors, resulting in lower statistical significance. This result is the outcome of a weaker first-stage, as indicated by lower values of the first-stage $F$-statistic and larger Wald and AR confidence intervals. ${ }^{16}$

Overall, Acemoglu et al. (2001)'s findings are robust to accounting explicitly for the uncertainty of the RL indicator. This could have been expected, given that the estimation exploits the cross-sectional variation in governance quality and, as discussed earlier, some countries have very different and non-overlapping governance values. Nevertheless, with multiple imputation, estimation of the parameter of interest is less precise, reflecting that the RL indicator is measured with uncertainty.

\footnotetext{
${ }^{15}$ When using multiple imputation, calculation of the first-stage $F$ statistic is straightforward. It simply involves running the first-stage regression and testing the statistical significance of the IV. For other instrument diagnostics, it is not clear how their statistics should be combined and interpreted. Roodman (2012) reports the median values of the tests of overidentifying restrictions $p$ values across 100 imputations and interpret them in the standard way. We report averages of the AR confidence intervals. However, in both cases, this is an $a d$ hoc practice without strong theoretical foundations. It may nevertheless provide information about the validity of the IV.

${ }^{16}$ Note that these confidence intervals are different from those implied by the second-stage standard errors because they do not account for the between-imputation variability.
} 
Table 4: Long-run development and governance

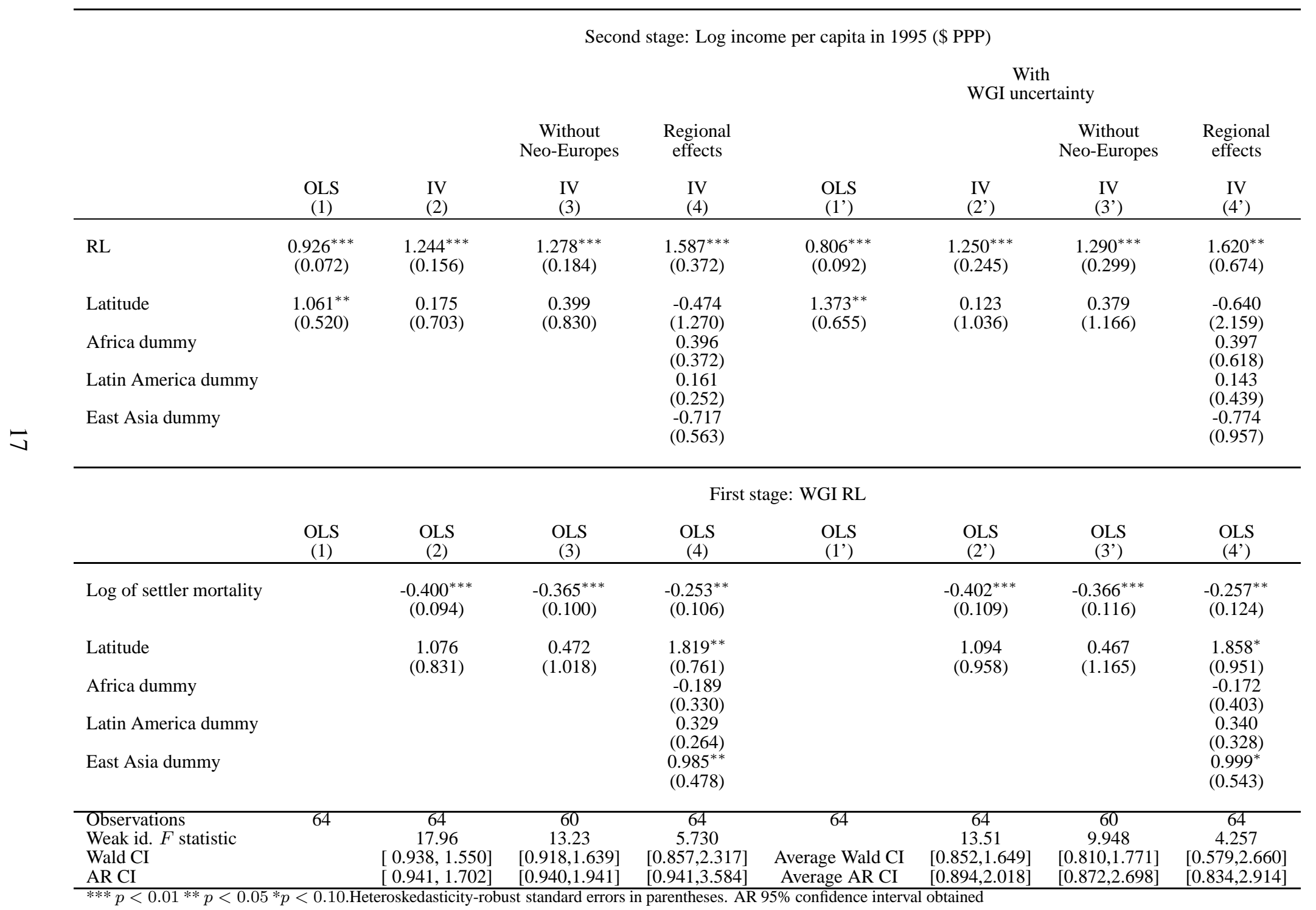

using an evenly spaced grid ranging from -20 to 20 containing 1000 points. 200 MI. 


\subsection{Income inequality and democracy}

\subsubsection{Data and empirical approach}

The impact of income inequality on democracy is a debated issue in the political literature. Boix (2003) argues that income equality promotes democracy whereas Acemoglu and Robinson (2006) suggest that there is an inverse U-relationship between income inequality and democratisation. In opposition to these redistributivist theories, Ansell and Samuels (2010) develop a 'contractarian' approach, which predicts a positive impact of income inequality on democratisation. Their empirical results support such a hypothesis. We revisit this debate by using recently produced proxies for democracy and income inequality. Unlike the WGI, which come with a standard error which we used to do multiple imputations, these variables come with imputations already provided.

Our data on democracy come from the Unified Democracy Scores (UDS) database. Like the WGI, the UDS scores are the outcome of a sophisticated integration of many different ratings of democracy into a single measure. Scores range from -2.14 to 2.33 , with a higher score indicating a more democratic political regime. Our data on income inequality correspond to the estimated Gini coefficients in the Standardized World Income Inequality Database (SWIID). The SWIID employs a custom missing-data algorithm to provide comparable estimates of the Gini index of gross (pre-tax, pre-transfer) and net (post-tax, post-transfer) income inequality. Gini coefficients range from 0.16 to 0.71 with a higher coefficient indicating greater inequality. ${ }^{17}$ In addition to a proxy, both UDS and SWIID provide imputed values of the variables. We directly use these values in our regressions. ${ }^{18}$

\footnotetext{
${ }^{17}$ The quality of the SWIID data has been questioned by Jenkins (2014) and others. However, much of this criticism relates to an older version of the SWIID database. We are using the most recent update of this dataset (see Solt (forthcoming)) which attempts to address some of these criticisms.

${ }^{18}$ We only use 100 imputations because that is the maximum number of imputed values provided with SWIID. Our previous applications used 200, but results were almost identical for 100 imputations (or 1000 imputations) indicating a high degree of robustness to the number of imputations.
} 
We build on the specification of Acemoglu et al. (2008) in column 6 of their Table 3. More precisely, using annual observations, we estimate a fixed effects panel data model, but use a wider variety of explanatory variables than Acemoglu et al. (2008). The dependent variable is a measure of democracy which is regressed on five lags of each of democracy, income inequality, and log of income per capita. Similar to Acemoglu et al. (2008), the lags are included to account for inertia in the political process. Year dummies are included in all regressions. Our sample covers 142 countries over the period 1960-2010. Standard errors are clustered at the country level.

\subsubsection{Empirical results}

Our results are presented in Table 5. We report the cumulative dynamic multipliers (sum of the coefficients on the lags) associated with each variable as well as the long-run effect of inequality on democracy. Column (1) assumes a linear relationship between democracy and gross income inequality while column (2) assumes a quadratic relationship. In columns (3) and (4), gross income inequality is replaced by net income inequality. Columns (1)' -(4') provide comparable multiple imputation results.

In column (1), the long-run effect of gross income inequality on democracy is positive, large, and statistically significant at the 5\% level (or 10\% level if we use bootstrapped standard errors). The point estimate suggests that a 10 point increase in inequality would increase democracy by a relatively small amount: 0.17 . In column (2) we investigate whether there exists a non-linear relationship between democracy and gross income inequality, by including a quadratic term in gross income inequality. This does not appear to be the case, given that the turning point corresponds to an extreme value of the Gini coefficient (greater than 0.53, the $95^{\text {th }}$ percentile). In column (3), the coefficient on net income inequality is larger than the coefficient on gross income inequality and achieves a higher level of statistical significance. 
Table 5: Democracy and income inequality

\section{Democracy (Unified Democracy Scores)}

Fixed effects estimator

With UDS/SWIID uncertainty

(1)

(3)

(4)

(1)

(2)'

(3)'

(4)

\begin{tabular}{|c|c|c|c|c|c|c|c|c|}
\hline & (1) & $(2)$ & (3) & (4) & (1) & (2) & (3) & (4) \\
\hline \multicolumn{9}{|l|}{$\begin{array}{l}\text { Cum. dynamic } \\
\text { multiplier }\end{array}$} \\
\hline Democracy & $\begin{array}{l}0.866 * * * \\
(0.016) \\
{[0.018]^{* * *}}\end{array}$ & $\begin{array}{l}0.865 * * * \\
(0.016) \\
{[0.018]^{* * *}}\end{array}$ & $\begin{array}{l}0.866 * * * \\
(0.017) \\
{[0.018]^{* * *}}\end{array}$ & $\begin{array}{l}0.865 * * * \\
(0.017) \\
{[0.018]^{* * *}}\end{array}$ & $\begin{array}{l}0.741 * * * \\
(0.031)\end{array}$ & $\begin{array}{l}0.738 * * * \\
(0.031)\end{array}$ & $\begin{array}{l}0.739 * * * \\
(0.031)\end{array}$ & $\begin{array}{l}0.736 * * * \\
(0.031)\end{array}$ \\
\hline $\ln (\mathrm{GDPPC})$ & $\begin{array}{l}-0.004 \\
(0.037) \\
{[0.038]}\end{array}$ & $\begin{array}{l}-0.002 \\
(0.039) \\
{[0.041]}\end{array}$ & $\begin{array}{l}-0.003 \\
(0.037) \\
{[0.037]}\end{array}$ & $\begin{array}{l}-0.000 \\
(0.039) \\
{[0.041]}\end{array}$ & $\begin{array}{l}-0.016 \\
(0.072)\end{array}$ & $\begin{array}{l}-0.012 \\
(0.073)\end{array}$ & $\begin{array}{l}-0.014 \\
(0.071)\end{array}$ & $\begin{array}{l}-0.006 \\
(0.073)\end{array}$ \\
\hline Gross Gini & $\begin{array}{l}0.234 * * \\
(0.112) \\
{[0.121]^{*}}\end{array}$ & $\begin{array}{l}0.671 \\
(0.904) \\
{[0.918]}\end{array}$ & & & $\begin{array}{l}0.290 \\
(0.217)\end{array}$ & $\begin{array}{l}1.313 \\
(1.513)\end{array}$ & & \\
\hline$(\text { Gross Gini) })^{2}$ & & $\begin{array}{l}-0.499 \\
(1.051) \\
{[1.065]}\end{array}$ & & & & $\begin{array}{l}-1.177 \\
(1.725)\end{array}$ & & \\
\hline Net Gini & & & $\begin{array}{l}0.328 * * * \\
(0.117) \\
{[0.130]^{* *}}\end{array}$ & $\begin{array}{l}0.728 \\
(0.764) \\
{[0.839]}\end{array}$ & & & $\begin{array}{l}0.505 * * \\
(0.239)\end{array}$ & $\begin{array}{l}1.680 \\
(1.422)\end{array}$ \\
\hline$(\text { Net Gini })^{2}$ & & & & $\begin{array}{l}-0.523 \\
(0.996) \\
{[1.092]}\end{array}$ & & & & $\begin{array}{l}-1.518 \\
(1.815)\end{array}$ \\
\hline \multicolumn{9}{|c|}{ Long-run effect } \\
\hline Gross Gini & $\begin{array}{l}1.747 * * \\
(0.868) \\
{[0.967]^{*}}\end{array}$ & & & & $\begin{array}{l}1.119 \\
(0.866)\end{array}$ & & & \\
\hline Net Gini & & & $\begin{array}{l}2.438^{* * *} \\
(0.919) \\
{[1.041]^{* *}}\end{array}$ & & & & $\begin{array}{l}1.939 * * \\
(0.964)\end{array}$ & \\
\hline Turning point & & 0.67 & & 0.70 & & 0.56 & & 0.55 \\
\hline Observations & 3139 & 3139 & 3139 & 3139 & 3139 & 3139 & 3139 & 3139 \\
\hline
\end{tabular}


In column (4), we do not find evidence of a non-linear relationship between net income inequality and democracy; the turning point is now higher than in column (2). Lastly, in all regressions, in line with the findings of Acemoglu et al. (2008), we find strong persistence of democracy over time as well as the absence of an impact of income per capita on democracy.

Some changes in these findings occur when we use multiple imputation methods to take into account the uncertainty of both UDS scores and Gini coefficients. In column (1'), gross income inequality no longer has a statistically significant effect of democracy in the long-run. In column (3'), the cumulative dynamic multiplier of net income inequality is larger than the comparable number of column (3), but estimated less precisely and, thus, is less significant. Furthermore, the estimate of the long-run effect of income inequality on democracy is smaller in column (3') than in column (3) because of a fall in the persistence of democracy. Finally, in columns (2') and (4'), the turning points are smaller than in columns (2) and (4). They remain extremely large and the marginal effects of (gross or net) income inequality when using a quadratic function are never statistically significant at conventional levels.

Overall, we find some supportive evidence for a positive and linear relationship between income inequality and democracy, as put forward by Ansell and Samuels (2010). However, using multiple imputation, this result only holds for a measure of net income inequality, suggesting that authoritarian rulers can appease demands for democracy through a redistribution of income. Hence our results appear to be compatible with a contractarian approach in which redistribution still plays a role.

\section{Conclusions}

Our applications have highlighted that the uncertainty around the values of various measures of political-economic development matters, since it can affect size and statistical significance 
of estimated parameters. Hence, when possible, this uncertainty ought to be fully acknowledged by using appropriate econometric methods such as multiple imputation. Such methods, fortunately, can be easily implemented using standard software. In addition, researchers constructing new data sets should be encouraged to provide standard errors along with their estimates. This additional information can be crucial in the investigation of key questions in economic development, such as the effects of governance on global economic integration or the determinants of democratisation. 


\section{References}

Acemoglu, Daron, Johnson, Simon, and Robinson, James A. (2001) 'The Colonial Origins of Comparative Development: An Empirical Investigation', American Economic Review, Vol. 91, pp. 1369-1401.

Acemoglu, Daron, Johnson, Simon, Robinson, James A., and Yared, Pierre (2008) 'Income and Democracy', American Economic Review, Vol. 98, pp. 808-842.

Acemoglu, Daron and Robinson, James A. (2006) Economic Origins of Dictatorships and Democracy: New York: Cambridge University Press.

Alfaro, Laura, Kalemli-Ozcan, Sebnem, and Volosovych, Vadym (2008) 'Why Doesn't Capital Flow from Rich to Poor Countries? An Empirical Investigation', Review of Economics and Statistics, Vol. 90, pp. 347-368.

Ansell, Ben and Samuels, David (2010) 'Inequality and Democratization: A Contractarian Approach', Comparative Political Studies, Vol. 43, pp. 1543-1574.

Azémar, Céline and Desbordes, Rodolphe (2013) 'Has the Lucas Paradox Been Fully Explained?', Economics Letters, Vol. 121, pp. 183-187.

Baier, Scott L. and Bergstrand, Jeffrey H. (2009) 'Bonus Vetus OLS: A Simple Method For Approximating International Trade-Cost Effects Using the Gravity Equation', Journal of International Economics, Vol. 77, pp. 77-85.

Beck, Thorsten, Demirguc-Kunt, Asli, and Levine, Ross (2009) 'Financial Institutions and Markets Across Countries and Over Time - Data and Analysis', Policy Research Working Paper Series No. 4943. 
Berden, Koen, Bergstrand, Jeffrey H, and Etten, Eva (2014) 'Governance and Globalisation', The World Economy, Vol. 37, pp. 353-386.

Binici, Mahir, Hutchison, Michael, and Schindler, Martin (2010) 'Controlling Capital? Legal Restrictions and the Asset Composition of International Financial Flows', Journal of International Money and Finance, Vol. 29, pp. 666-684.

Boix, Carles (2003) Democracy and Redistribution: New York: Cambridge University Press.

Bolt, J. and van Zanden, J. L. (2013) 'The First Update of the Maddison Project; ReEstimating Growth Before 1820’, Maddison Project Working Paper 4.

Chernozhukov, Victor and Hansen, Christian (2008) 'The Reduced Form: A Simple Approach to Inference with Weak Instruments', Economics Letters, Vol. 100, pp. 68-71.

Daude, Christian and Stein, Ernesto (2007) 'The Quality of Institutions and Foreign Direct Investment', Economics and Politics, Vol. 19, pp. 317-344.

Faria, Andre and Mauro, Paolo (2009) 'Institutions and the External Capital Structure of Countries', Journal of International Money and Finance, Vol. 28, pp. 367-391.

Head, Keith, Mayer, Thierry, and Ries, John (2010) 'The Erosion of Colonial Trade Linkages After Independence', Journal of International Economics, Vol. 81, pp. 1-14.

Høyland, Bjørn, Moene, Karl, and Willumsen, Fredrik (2012) 'The Tyranny of International Index Rankings', Journal of Development Economics, Vol. 97, pp. 1-14.

Jenkins, Stephen P. (2014) 'World Income Inequality Databases: An assessment of WIID and SWIID', IZA Discussion Paper, No. 8501.

Kaufmann, Daniel and Kraay, Aart (2002) 'Growth Without Governance', Economia, Vol. 3, pp. 169-229. 
Kaufmann, Daniel, Kraay, Aart, and Mastruzzi, Massimo (2009) 'Governance Matters VIII: Aggregate and Individual Indicators, 1996-2008', World Bank Policy Research Paper, No. 4978.

(2011) 'The Worldwide Governance Indicators: Methodology and Analytical Issues', Hague Journal on the Rule of Law, Vol. 3, pp. 220-246.

Kaufmann, Daniel, Kraay, Aart, and Zoido-Lobaton, Pablo (1999) ‘Aggregating Governance Indicators', World Bank Working Paper, No. 2195.

Lane, Philip R. and Milesi-Ferretti, Gian Maria (2007) 'The External Wealth of Nations Mark II: Revised and Extended Estimates of Foreign Assets and Liabilities, 1970-2004', Journal of International Economics, Vol. 73, pp. 223-250.

Milner, Helen V and Mukherjee, Bumba (2009) 'Democratization and Economic Globalization', Annual Review of Political Science, Vol. 12, pp. 163-181.

Pemstein, Daniel, Meserve, Stephen A, and Melton, James (2010) 'Democratic Compromise: A Latent Variable Analysis of Ten Measures of Regime Type', Political Analysis, Vol. 18, pp. $426-449$.

Rodrik, Dani, Subramanian, Arvind, and Trebbi, Arvind (2004) 'Institutions Rule: The Primacy of Institutions Over Geography and Integration in Economic Development', Journal of Economic Growth, Vol. 9, pp. 131-165.

Roodman, David (2012) 'Doubts About the Evidence That Foreign Aid For Health is Displaced Into Non-Health Uses', The Lancet, Vol. 380, pp. 972-973.

Rubin, Donald B (1996) 'Multiple Imputation After 18+ years', Journal of the American Statistical Association, Vol. 91, pp. 473-489. 
Solt, Frederick (forthcoming) 'The Standardized World Income Inequality Database', Social Science Quarterly.

Staiger, Douglas and Stock, James H. (1997) 'Instrumental Variables Regression with Weak Instruments', Econometrica, Vol. 65, pp. 557-586.

Standaert, Samuel (forthcoming) 'Divining the Level of Corruption: A Bayesian State-Space Approach', Journal of Comparative Economics.

Treisman, Daniel (2007) 'What Have We Learned About the Causes of Corruption From Ten Years of Cross-National Empirical Research?', Annual Review of Political Science, Vol. 10, pp. 211-244.

Wooldridge, Jeffrey M. (2010) Econometric Analysis of Cross Section and Panel Data: Cambridge, MA: The MIT Press, second edition. 


\section{Appendices}

\section{A Description of variables}

The variables used in the empirical applications are described in Table 6.

\section{B Stata pseudo-code}

We present below how the uncertainty around the WGI estimate Voice and Accountability can be taken into account in Stata, using multiple imputation.

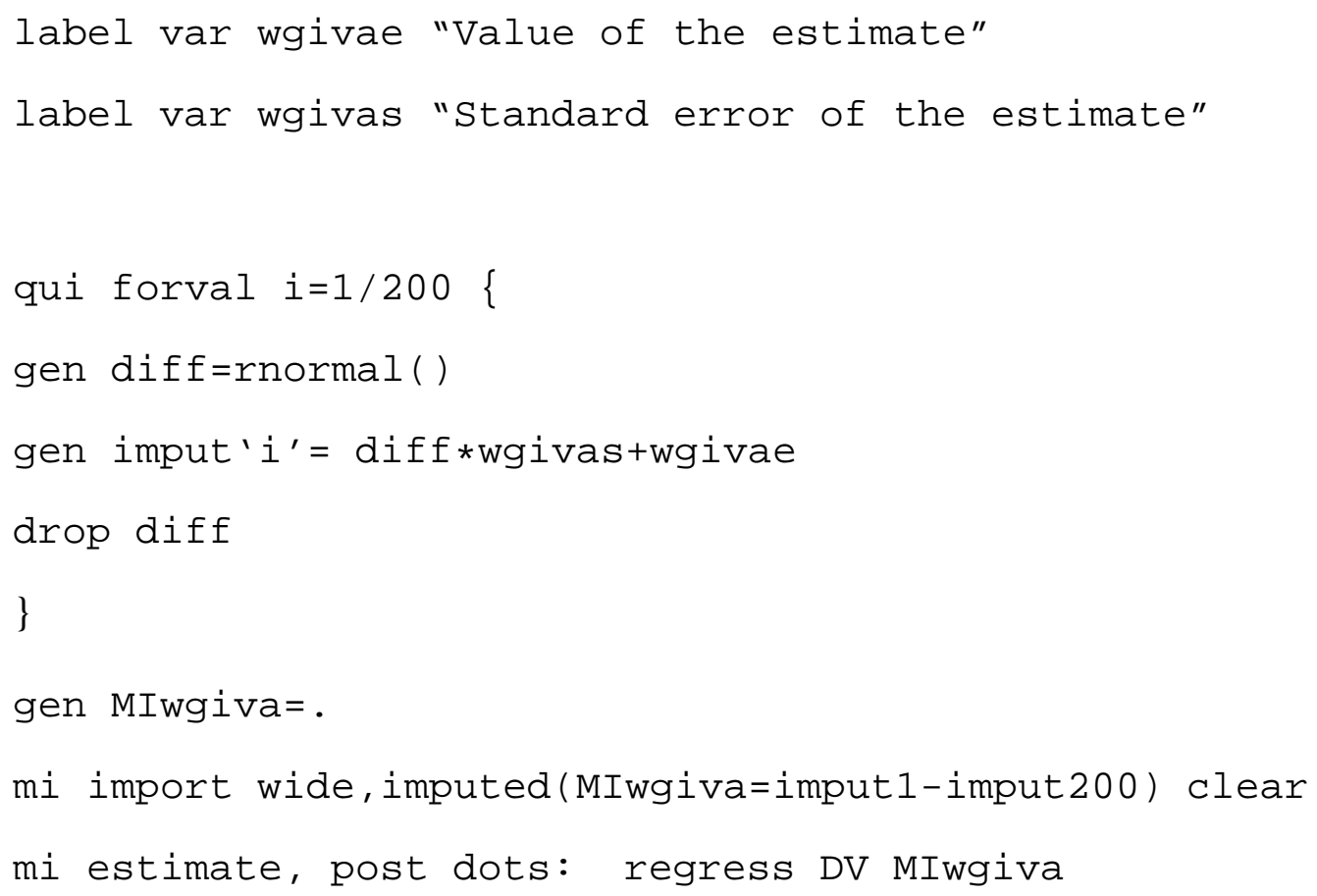


Table 6: Description of variables

\begin{tabular}{|c|c|c|c|}
\hline Application & Variable & Description & Source \\
\hline $\begin{array}{l}\text { WGI } \\
1996-2010\end{array}$ & Worldwide Governance Indicators (WGI) & Six Worldwide Governance Indicators (VA, PS, GE, RQ, RL, CC) & $\begin{array}{l}\text { WGI project } \\
\text { (www.govindicators.org) }\end{array}$ \\
\hline $\begin{array}{l}\text { Capital flows } \\
71 \text { countries } \\
1998-2005 \\
\text { WGI }(1998,2000,2002-2005)\end{array}$ & $\begin{array}{l}\text { Capital inflows (debt or equity) } \\
\text { Capital outflows (debt or equity) } \\
\text { Capital in/out-flow control } \\
\text { Population } \\
\text { GDP per cap } \\
\text { (Fuel, Metals, Ore)/ Exports } \\
\text { Trade openness } \\
\text { Private credit/GDP } \\
\text { STMK CAP/GDP }\end{array}$ & $\begin{array}{l}-\min (\Delta \text { assets, } 0)+\max (\Delta \text { liabilities, } 0) \text {; per capita, in US \$ } \\
\text { max }(\Delta \text { assets, } 0)-\min (\Delta \text { liabilities, } 0) \text {; per capita, in US } \$ \\
\text { Index of financial openness }(0-1, \text { from least to most regulated }) \\
\text { Total population } \\
\text { GDP per capita, in constant } 2000 \text { US \$ } \\
\text { Sum of the fuel, metals and ore exports divided by total exports } \\
\text { (Exports+Imports)/GDP } \\
\text { Private credit by deposit money banks and other financial institutions to GDP } \\
\text { Value of listed shares to GDP }\end{array}$ & $\begin{array}{l}\text { Lane and Milesi-Ferretti (2007) } \\
\text { Lane and Milesi-Ferretti (2007) } \\
\text { Schindler (2009) } \\
\text { World Development Indicators } \\
\text { World Development Indicators } \\
\text { World Development Indicators } \\
\text { World Development Indicators } \\
\text { Beck et al. (2009) } \\
\text { Beck et al. (2009) }\end{array}$ \\
\hline $\begin{array}{l}\text { International trade } \\
180 \text { countries } \\
1998-2004 \\
\text { WGI }(1998,2000,2002-2004)\end{array}$ & $\begin{array}{l}\text { GDP } \\
\text { GDPPC } \\
\text { Bilateral trade flows } \\
\text { Distance } \\
\text { Contiguity } \\
\text { Common language } \\
\text { Colonial links } \\
\text { Multilateral resistance (MR) terms }\end{array}$ & $\begin{array}{l}\text { GDP, in constant } 2000 \text { US } \$ \\
\text { GDP per capita, in constant } 2000 \text { US } \$ \\
\text { Exports from country } i \text { to country } j \\
\text { Population-weighted bilateral distance }(\mathrm{km}) \\
1 \text { if two countries share a common border } \\
1 \text { if a language is spoken by at least 9\% of the population in both countries } \\
1 \text { for pair even in colonial relationships } \\
\text { Calculated following Baier and Bergstrand (2009) }\end{array}$ & $\begin{array}{l}\text { World Development Indicators } \\
\text { World Development Indicators } \\
\text { Head et al. (2010) } \\
\text { Head et al. }(2010) \\
\text { Head et al. }(2010) \\
\text { Head et al. (2010) } \\
\text { Head et al. (2010) }\end{array}$ \\
\hline $\begin{array}{l}\text { Income levels } \\
64 \text { countries } \\
1995 \\
\text { WGI RL only (1996) }\end{array}$ & $\begin{array}{l}\text { Log of income per capita } \\
\text { Latitude } \\
\text { Settler mortality } \\
\text { Regional dummy variables }\end{array}$ & $\begin{array}{l}\text { Income per capita in } 1995 \text { (\$PPP basis) } \\
\text { Absolute value of the latitude of the country } \\
\text { Estimated settlers' mortality rate } \\
\text { Regional indicators for Africa, East-Asia, Latin America and the Caribbean }\end{array}$ & $\begin{array}{l}\text { Acemoglu et al. (2001) } \\
\text { (http:///economics.mititedu/faculty/acemoglu/data/ajr2001) } \\
\text { Acemoglu et al. (2001) } \\
\text { Acemoglu et al. (2001) } \\
\text { Rodrik et al. (2004) }\end{array}$ \\
\hline $\begin{array}{l}\text { Democracy and Income inequality } \\
142 \text { countries } \\
1960-2010\end{array}$ & $\begin{array}{l}\text { Democracy } \\
\text { Income inequality }\end{array}$ & $\begin{array}{l}\text { Unified Democracy Scores } \\
\text { Gross and net (post-tax, post-transfer) income inequality }\end{array}$ & $\begin{array}{l}\text { Pemstein et al. (2010) } \\
\text { (http://www.unified-democracy-scores.org/) } \\
\text { Solt (forthcoming); version 5, updated October 2014 } \\
\text { (http://myweb.uiowa.edu/fsolt/swiid/swiid.html) } \\
\text { Bolt and van Zanden (2013) }\end{array}$ \\
\hline
\end{tabular}

